\title{
humanidades
}

Revista humanidades

Diciembre, $2014 \cdot$ Volumen $4 \cdot \operatorname{ISSN} 2215-3934 \cdot$ pp. 1-15

\section{Teatro como acontecimento: La importancia del error y del inacabamiento de las cosas en la pedagogía teatral}

DOI: http://dx.doi.org/10.15517/h.v4i1.16326

Recibido: 10-Junio-2014 / Aceptado: 12-Agosto-2014

\section{Juan Carlos Calderón Gómez}

Máster, Coordinador de la Sección de Arte en la Escuela de Estudios Generales de la Universidad de Costa Rica.

Correo electrónico: calderon.juancarlos@gmail.com 


\section{Teatro como acontecimento: La importancia del error y del inacabamiento de las cosas en la pedagogía teatral}

\section{Resumen}

Esta reflexión recoge parte de la experiencia metodológica utilizada en mi trabajo como docente en la Universidad de Costa Rica. Se expone cómo los procesos pedagógicos teatrales contribuyen a formar una persona reflexiva, lúdica y con conciencia de la importancia del trabajo en equipo.

Palabras clave: Teatro universitario, pedagogía teatral.

\section{Teatro como acontecimento: The importance of error and of the unfinished in drama education}

\section{Abstract}

This reflection includes part of my methodological experience used in my teaching position at the University of Costa Rica. We intend to demonstrate how dramatic pedagogical processes contribute to foster thoughtfulness, playfulness and the awareness of the importance of teamwork.

Keywords: University theater, theater pedagogy. 
Jorge Dubatti (2011) en su propuesta filosófica ahonda en el concepto del teatro como acontecimento. El teatro como acontecimento no comunica estrictamente, a pesar de mantener los elementos fundamentales del proceso de comunicación (emisor, receptor y mensaje), sostiene el filósofo, sino que el teatro como acontecimento estimula, incita y provoca:

El teatro como acontecimento, es mucho más que el conjunto de las prácticas discursivas de un sistema lingüístico, excede la estructura de signos verbales y no verbales, el texto y la cadena de significantes a los que se reduce para una supuesta comprensión semiótica. En el teatro, como acontecimento, no todo es reductible a lenguaje (Dubatti, 2011, p.16).

Luis de Tavira (1999), a su vez, insiste en la autonomía del género teatral sobre la vida:

$[\ldots]$ por vertientes misteriosas confluyentes, por asimilaciones ocultas ha venido surgiendo un teatro que se propone inventar la realidad, citar el acontecimiento en un mundo de simulacros, donde la vida imita la ficción. Un teatro que halla su sentido en el descubrimiento del sinsentido de la historia (De Tavira, 1999, p. 21). 
Esta idea de que la imaginación precede al habla y que el teatro contiene la verdad que la vida no tiene, se relaciona a la propuesta de Herbert Read (1963), que le otorga al arte la función primaria en la evolución de todas las facultades superiores que constituyen la cultura humana. De igual forma, se acerca a los aportes de Carmen Nogueira (2001), sobre la teoría de recepción y el cambio paradigmático del arte en la Postmodernidad y la representación Post-histórica que se resiste a una interpretación cerrada a sí misma.

Aunque existe una polaridad entre ellas (realidad y representación), no son excluyentes, la representación se dirige hacia la realidad, es algo que no existe sino como tendencia. Al final la función de la representación no es ser realidad, sino mostrar un modo de conocimiento, es decir, una idea concreta y determinada [...] El modelo de representación, que hemos localizado en nuestra investigación, nos permite acercarnos a la realidad, aunque no completarla, es un conocimiento relativo, que permite mostrar esa relación (Nogueira, 2001, p. 63).

El teatro como acontecimento reafirma este carácter primigenio del arte en general y del teatro en particular, esta función ontológica del teatro que sorprende en su voluntad al ser humano, replantea la función estética de recrear o re-presentar y la sustituye por la de "sentar", la que pone un mundo a existir, a hacer nacer un nuevo ente (Dubatti, 2011). 
A estas propuestas ontológicas debemos agregar la variante, siempre cambiante y en continua dinámica, del entorno cultural y teatral, "transformando constantemente la palabra teatral como consecuencia de la incorporación acelerada de la imagen y del sonido a las prácticas cotidianas de comunicación social" (Thenon, 2002, p. 173).

La pedagogía teatral, en su universo de posibilidades creativas, nos muestra dos opciones. La primera se refiere a la pertinencia del teatro como instrumento pedagógico que acompaña procesos interdisciplinarios, terapéuticos, marginales, cognitivos, desde las propuestas del teatro infantil, hasta las dramatizaciones holísticas en edades mayores. La segunda opción profundiza en la enseñanza del teatro como medio y como fin profesional, sin negar su carácter liberador en sí mismo y su potencial en procesos interdisciplinarios.

Hemos implementado, en nuestras clases de Taller de Teatro en la Escuela de Estudios Generales, la primera opción; sin embargo, existen elementos importantes - al revisar el teatro como disciplina profesional- que se incorporan activamente en la clase, como lo plantea la exigencia de la representación final del proceso artístico ante un público. 
En el siguiente cuadro comparativo, Verónica García (citada en García-

Huidobro, s.f., p. 10) describe las diferencias fundamentales entre ambas

metodologías y visiones pedagógicas:

\section{Diferencias entre el juego dramático y el teatro}

\begin{tabular}{|c|c|}
\hline Juego dramático & Representación teatral \\
\hline Se realiza en el aula o en cualquier espacio amplio & Se necesita el escenario teatral \\
\hline $\begin{array}{c}\text { Se desarrolla a partir de un proyecto oral que puede ser } \\
\text { variado }\end{array}$ & $\begin{array}{c}\text { Se desarrolla a partir de una obra dramática } \\
\text { generalmente escrita }\end{array}$ \\
\hline Los roles son auto-designados por los participantes & Los roles son impuestos por la dirección \\
\hline
\end{tabular}

Las acciones y los diálogos son improvisados por los participantes

Los movimientos y el texto son aprendidos por los actores o actrices

Los actores/actrices y el público son intercambiables

Los actores/actrices y el público están diferenciados

El facilitador estimula el avance de la acción

La dirección planea el desarrollo de la obra

El juego dramático puede no concretarse, si el tema no alcanza el desarrollo necesario

La obra dramática tiene una estructura prevista que debe concretarse

Significa destacar el desarrollo y realización del proyecto que movió al grupo

Significa destacar la presentación final de la obra dramática escrita

Se valoriza el proceso de aprendizaje, es lo más significativo

No existe el concepto de fracaso

Existe el concepto de fracaso

Se evalúa el espectáculo como resultado final 
La fase lúdica es primordial en el fenómeno dramático y en la didáctica teatral; ineludiblemente, se aplica a ambas propuestas, con el juego y la posibilidad de ser otro; metamorfoseándose en la otredad, el actor personifica la esencia del teatro.

El Ministerio de Educación de Chile, en su propuesta para incluir al teatro como materia obligatoria en secundaria, acertadamente justifica su decisión de la siguiente manera:

La propuesta curricular en Artes Escénicas [...] está centrada en la importancia del juego y la expresión dramática, tanto espontánea como organizada. El propósito es potenciar la capacidad lúdica como un medio para conocerse a sí mismo, indagar el entorno circundante e introducirse en los elementos que constituyen la teatralidad, según la etapa de desarrollo de cada grupo etario. En este nivel se inicia una aproximación teórico-práctica que instala el concepto de representación, experimentando los contenidos propios del lenguaje teatral, la apreciación crítica y la mirada sensible de la realidad estética (MINEDUC, 2007, p. 4). 
Nuestra experiencia con estudiantes universitarios de diferentes carreras y de distintos niveles, con una población comprendida entre los 18 y 28 años, nos permite emplear los dos enfoques de enseñanza, en el marco de una concepción humanista, ecologista e integral del mundo y de las cosas y de los seres que coexisten en él.

La forma de atender al teatro como instrumento de crecimiento y de percepción positiva de sí mismo, permite:

[...] mantener y sanear los vínculos entre las personas con discapacidad (social, física, y/o mental) y su medio ambiente, perfeccionando y complementando los hábitos adquiridos para potenciar sus habilidades sociales, capacidad laboral, diversidad y posible inserción en la sociedad (García-Huidobro, 2004, p. 18).

Al parecer, la diferencia fundamental entre un enfoque y el otro está en la propuesta competitiva y de excelencia del primero, frente al espacio de recreación que propone el segundo.

El carácter lúdico y efímero del hecho teatral, el error visto como acierto y la posibilidad de crecimiento integral, como propuesta pedagógica fundamental en la creación y en el acompañamiento del fenómeno, así como la 
implementación de disciplina individual y grupal y la negación del fracaso en la experiencia dramática, se constituyen en los pilares fundamentales del trabajo del docente en artes dramáticas. La competitividad desaparece en la medida en que no está en juego el futuro profesional.

Otros de los conceptos incorporados en la dinámica de las lecciones es el carácter de inacabado que tiene un proceso creativo. En cada ensayo se avanza, aun cuando alguno que otro paralice las dudas y la conciencia de que el camino puede ser otro; se convierte, por ello, en un avance y no en una frustración, en donde las funciones son crecimiento ininterrumpido. Si bien la puesta en escena es efímera, años después se descubren imágenes que impactan a los estudiantes y, por su parte, el público que la apreció recuerda o incorpora, en forma intensa, algunos de sus pasajes, por lo que:

Por ello, es preciso que en la educación y en el aprendizaje se tome en cuenta la problemática de la conciencia del inacabamiento en el obrar. Para que toda obra y proyecto no oculte su brecha sino que la señale. Esto no significa relajar la disciplina intelectual, sino invertir su sentido consagrándola a la realización del inacabamiento como experiencia de vida (Morin, 2002, p. 47). 
Desde el principio, el objetivo fundamental del TALLER DE TEATRO fue el montaje de, al menos, una puesta en escena al finalizar el curso, para mostrar a un público.

Las innumerables creaciones colectivas que se iniciaron con procesos de investigación, recurren a espacios públicos y privados que nacen de la necesidad de decir, de articular y de montar imágenes e historias en creaciones colectivas para comunicar, epidérmica y racionalmente, las inquietudes, las necesidades y las incertidumbres propias del trabajo creativo y su representación:

La representación teatral posee el don de hacer interactuar diferentes códigos artísticos, respetando sus propios lenguajes, con el objeto de producir un discurso propio con múltiples portales de acceso de orden sensorial, afectivo, intelectual y valórico. Desde el origen podemos deducir el enorme potencial integrador que posee el arte del teatro como mediador de la alfabetización artística, promoviendo procesos y resultados interactivos de elaboración escénica y síntesis crítica (MINEDUC, 2007, p. 7).

No hay duda de que el ejercicio del teatro, en la educación, mejora el poder de concentración del estudiante, debido a la exposición que se tiene de sí mismo ante el colectivo y ante un público. Igualmente, le permite desarrollar la 
habilidad de observar, registrar y recrear las diferentes realidades en las que vive, así como acrecentar la capacidad de trabajar en equipo, la habilidad para expresar ideas recurriendo a la metáfora de la teatralidad y al uso de una técnica mayormente expresiva, la cual le hace descubrir sus potencialidades creadoras y que trasciende lo teatral para enfrentar lo artístico: el canto, el baile, el diseño, la arquitectura, la fotografía, la pintura, la escultura, la cerámica, el maquillaje, el vestuario, las luces, la banda musical y su manipulación, las que confluyen en la habilidad de plantear discursos estéticos y poder expresarlos teatralmente.

El error es valorar el teatro como instrumento indispensable de la creación; no solo es celebrado sino valorado, ya que se presenta, la mayoría de la veces, como una voz potente que viene desde el inconsciente creativo y que obliga al docente-facilitador del espectáculo a no dejar pasar libremente; tiene que ser un maestro en el arte de asir estas manifestaciones y evidenciarlas no solo al ejecutante o al intérprete sino, también, al colectivo.

Una vez establecida toda la información teórica y de recursos vivenciales al servicio del "otro" que es el personaje y producto de la resistencia a recibir un estímulo equivocado del personaje o de la situación dramática de otras voces que se establecen en el proceso, la voz interior reacciona exigiendo su espacio en esa toma de decisiones: proxénicas, kinestésicas, lingüísticas y afectivas y, ante su imposibilidad jerárquica o clínica, adopta y aparece la figura del error. 
El error, como instrumental dramático, llega a ser revelador y, lejos de mostrar una distracción creadora, se apodera del espacio escénico de una manera elocuente y eficaz. Esta experiencia educativa luego se traslada a otras actividades del sujeto creador que tienen repercusión en su vida y sobre esta. El error es un fenómeno eminentemente artístico que recoge la educación y lo instrumentaliza al servicio de la experiencia académica y de la vida: Colón descubre América y piensa que está en la India, no importa qué descubre, lo importante es que descubre "algo" que altera la historia de dos grandes mundos. El error produce cambios sustanciales en el sujeto creador los cuales le provocan satisfacción y deseos de seguir explorando y de emprender otros viajes. El error facilita la caída, aquí entendida como la luz creativa.

El teatro, como instrumento, propone una metodología activa en donde todo es relacionado con el mundo perceptivo y emocional de las personas. En la experiencia del TALLER DE TEATRO se prioriza al ser humano y, por eso, no se establece un enunciado demoledor contra la dignidad de la persona, confrontado con un entorno, la mayoría de las veces hostil y mercantilista. En el teatro, como espacio lúdico, la función puede suspenderse, ya que lo importante es la persona en realidad; es así como se evidencia la actitud educativa incluso más que la técnica pedagógica.

La alerta corporal, vocal y, sobre todo, sensitiva es desarrollada en los ejercicios y en los ensayos para reflexionar y compartir con todos, porque a todos les ha pasado generalmente las mismas cosas cuando se emplea la técnica 
teatral; así, el uso del espacio íntimo, personal y social, las inflexiones de voz, el poder de la mirada, la música de los textos, la presencia escénica, la cadencia rítmica y la capacidad de juego son interiorizadas en la huella corporal a partir de la vivencia en el espacio escénico.

Así se entiende la enseñanza del teatro como una oportunidad única para crecer emotiva, sensitiva y racionalmente. El Ministerio de Educación debería pensar seriamente en incorporar esta disciplina en la malla curricular del estudiante de primaria de secundaria, como lo están haciendo algunos centros educativos privados en nuestro país. De esa manera, fortalecer la capacidad de juego, el trabajo en equipo y los procesos creativos de las personas que se exponen a esta experiencia lúdica-reflexiva, intensa y liberadora. 
Delors, J. (1995). La educación encierra un tesoro. Informe a la Unesco de la Comisión Internacional sobre la Educación en el siglo XXI. Francia: Ediciones Unesco.

De Tavira, L. (1999). El Espectáculo invisible: Paradojas sobre el arte de la actuación. Madrid: Publicaciones de la Asociación de Directores de Escena de España.

Dubatti, J. (2011). Introducción a los estudios teatrales. México DF: Libros de Godot.

García-Huidobro, V. (2004). Pedagogía teatral: metodología activa en el aula. Santiago de Chile S. A.

Ministerio de Educación de Chile (MINEDUC). (2007). Artes Escénicas Teatro. Programa de Estudio. Plan Diferenciado Tercer o Cuarto Año Medio. Escuelas Artísticas. Objetivos y contenidos adicionales de formación artística. Enseñanza Básica y Primer Ciclo de Enseñanza media. Disponible en: http://www.educrea.cl/otec/pdfs/instrumentos_curriculares_mi neduc/EDUCACION_BASICA_Y_MEDIA/MARCOS_CUR RICULARES/marco-curricular-formacion-diferenciadaartistica.pdf

\section{Referencias bibliográficas}


Morin, E. y otros. (2002). Educar en la era planetaria. Barcelona, España: Gedisa S. A. Editorial.

Nogueira, C. (2001). La representación como puesta en escena para una teoría de la mirada. Valencia: Diputación de Valencia Institució Alfons el Magnànim.

Read, H. (1963). Imagen e idea: la función del arte en el desarrollo de la conciencia humana. Traducción Horacio Flores. México: Fondo de Cultura económica. 